\title{
Editorial favoritism in the field of laboratory experimental economics (RM/20/014-revised-)
}

Citation for published version (APA):

Cloos, J., Greiff, M., \& Rusch, H. (2021). Editorial favoritism in the field of laboratory experimental economics (RM/20/014-revised-). Maastricht University, Graduate School of Business and Economics. GSBE Research Memoranda No. 005 https://doi.org/10.26481/umagsb.2021005

Document status and date:

Published: 17/03/2021

DOI:

10.26481/umagsb.2021005

Document Version:

Publisher's PDF, also known as Version of record

\section{Please check the document version of this publication:}

- A submitted manuscript is the version of the article upon submission and before peer-review. There can be important differences between the submitted version and the official published version of record.

People interested in the research are advised to contact the author for the final version of the publication, or visit the DOI to the publisher's website.

- The final author version and the galley proof are versions of the publication after peer review.

- The final published version features the final layout of the paper including the volume, issue and page numbers.

Link to publication

\footnotetext{
General rights rights.

- You may freely distribute the URL identifying the publication in the public portal. please follow below link for the End User Agreement:

www.umlib.nl/taverne-license

Take down policy

If you believe that this document breaches copyright please contact us at:

repository@maastrichtuniversity.nl

providing details and we will investigate your claim.
}

Copyright and moral rights for the publications made accessible in the public portal are retained by the authors and/or other copyright owners and it is a condition of accessing publications that users recognise and abide by the legal requirements associated with these

- Users may download and print one copy of any publication from the public portal for the purpose of private study or research.

- You may not further distribute the material or use it for any profit-making activity or commercial gain

If the publication is distributed under the terms of Article $25 \mathrm{fa}$ of the Dutch Copyright Act, indicated by the "Taverne" license above, 
Janis Cloos, Matthias Greiff,

Hannes Rusch

Editorial favoritism in the field of laboratory experimental economics

(RM/20/014-revised-)

RM/21/005

ISSN : 2666-8807

\section{GSBE}

Maastricht University School of Business and Economics

Graduate School of Business and Economics

P.O Box 616

NL- 6200 MD Maastricht

The Netherlands 


\title{
EDITORIAL FAVORITISM IN THE FIELD OF LABORATORY EXPERIMENTAL ECONOMICS*
}

\author{
Janis Cloos, Matthias Greiff, and Hannes Rusch ${ }^{凶}$
}

\begin{abstract}
We examine scientific quality and editorial favoritism in the field of experimental economics. We use a novel data set containing all original research papers $(N=569)$ that exclusively used laboratory experiments for data generation and were published in the American Economic Review (AER), Experimental Economics (EE), or the Journal of the European Economic Association (JEEA) between 1998 and 2018. Several proxies for scientific quality indicate that experiments conducted in Europe are of higher quality than experiments conducted in the US: European experiments rely on larger numbers of participants as well as participants per treatment and receive more citations. For the AER and the JEEA, but not for EE, we find that papers authored by economists with social ties to the editors receive significantly fewer citations in the years following publication. Detailed analyses using a novel dynamic and continuous measure of the co-authorship distance between editors and authors imply that authors at longer distances to editors have to write papers of higher quality in order to get published in the AER and the JEEA. We find no evidence that this 'uphill battle' is associated with geographical distance. (JEL: A11, A14, C90, I23)
\end{abstract}

Keywords: laboratory experiments, favoritism, methodological standards, network effects

\footnotetext{
* Data, code and readme file available upon request from the authors.

$\bowtie$ Correspondence to: Janis Cloos, Institute of Management and Economics, Clausthal University of Technology, Julius-Albert-Str. 2, 38678 Clausthal-Zellerfeld, Germany; Fax: +49 532372 7698, Telephone: +49 5323727673 , E-Mail: janis.cloos@tu-clausthal.de. Janis Cloos is a PhD student at the chair of Behavioral Management and Economics at the Clausthal University of Technology, Germany. Matthias Greiff is professor for Behavioral Management and Economics at the Clausthal University of Technology, Germany, matthias.greiff@tuclausthal.de. Hannes Rusch is assistant professor at the Microeconomics and Public Economics Department at Maastricht University, Netherlands, h.rusch@maastrichtuniversity.nl.

Acknowledgments: We thank Max Albert, Jeanette Brosig-Koch, Gary Charness, Björn Frank, Daniel Hamermesh, Sebastian Kruegel, Sarah Necker, the participants of the ASSA/AEA 2021 Virtual Annual Meeting, the participants of the 2020 Virtual Annual Meeting of the German Economic Association (Verein für Socialpolitik), the participants of the 2019 Economic Science Association (ESA) North American Meeting in Los Angeles, the participants of the $14^{\text {th }}$ Nordic Conference on Behavioral and Experimental Economics in Kiel, the participants of the 2017 Annual Meeting of the German Association for Experimental Economic Research (GfeW e.V.) in Kassel, and seminar participants at the University of Portsmouth, University of Passau, HSU Hamburg and the University of Marburg for feedback and comments. Simone Koch provided excellent research assistance.
} 


\section{Introduction}

The editorial process is a crucial element in scientific competition. Authors compete for sparse space in journals, ideally leading to only the best manuscripts being accepted for publication. Across journals, editors compete because each editor wants to maximize the quality of her journal by publishing the best papers (Card and DellaVigna, 2020). If decisions about acceptance and rejection are made solely based on the quality of the manuscript, competition ensures that optimal outcomes are achieved. The resulting allocation is efficient in the sense that the best rejected manuscript is of lower quality than the worst accepted manuscript. In judging the quality of a submitted manuscript, editors play a crucial role. However, when editorial decisions are not based on scientific criteria alone but also on others, such as authors' social ties to editors, outcomes might be inefficient and scientific progress might suffer.

Editorial favoritism is a problem, thus, when the quality of published research is negatively affected, i.e., when papers written by an editor's colleagues or former co-authors are published while better papers by other scholars are rejected. High shares of published papers by authors who are connected to at least one of a given journal's editors are often taken as an indication for editorial favoritism. However, this is neither necessary nor sufficient. As pointed out by Brogaard et al. (2014, p. 252), the decisive question is "[ ...] whether editors use information advantages to improve selection decisions, or whether they bow to conflicts of interest."

Existing studies on effects of author-editor connections (i.e. social ties) use papers published in - usually high ranking general interest - journals (Colussi, 2018; Brogaard et al., 2014; Medoff, 2003; Laband and Piette, 1994a). The studies by Colussi (2018) and Brogaard et al. (2014) show that the number of papers an author publishes in a given journal increases significantly as soon as a close colleague becomes an editor at that journal. Brogaard et al. (2014), Medoff (2003), and Laband and Piette (1994a) show that papers by authors with social ties to editors on average receive significantly more citations in the years following publication. However, the results of Laband and Piette (1994a) also show that more than two thirds of the papers with remarkably few citations were written by authors who had social ties to the editors.

Taken together, the results from previous studies suggest that (1) social ties can improve the chances of getting published because they reduce editors' search costs for high-quality papers, 
and (2) that, conditional on being accepted for publication papers by authors with social ties to editors receive more citations on average.

Most of the existing literature on editorial favoritism proxies the quality of papers solely ex post, i.e. based on the number of citations a paper receives in the years following publication. Then, previous work typically assesses how the number of citations is affected by social ties, authors' reputation, paper length, JEL codes, and journal. In the field of experimental economics, however, several characteristics of an experiment - such as the number of participants, the number of participants per treatment, the number of treatments, and the strength of monetary incentives - constitute ex ante proxies for an experiment's quality which typically also affects the respective paper's quality.

While the role of such experimental characteristics has been discussed from a methodological perspective, their role in the in the editorial process has not been studied yet. With this paper, we fill that gap. Our analyses cover all laboratory experiments published between 1998 and 2018 in the American Economic Review (AER), arguably one of the top journals for general economics worldwide, Experimental Economics (EE), the top field journal, and the Journal of the European Economic Association (JEEA), arguably one of the European top journals for general economics.

Our focus on experimental economics allows us to examine (1) whether papers written by authors from different geographical regions differ with respect to several ex ante proxies capturing the scientific quality of the experiments, and (2) whether social ties between editors and authors have an effect on the ex post quality of papers (measured in citations) when we control for ex ante quality proxies.

Our results show substantial differences between Europe and the US, the two regions where more than $82 \%$ of the experiments in our dataset were conducted. For all three journals, experiments conducted in Europe have larger average numbers of participants per treatment. In the AER and in EE, experiments conducted in Europe also have a larger average total number of participants. We also find that AER and EE papers that include experiments conducted in Europe receive significantly more citations in the years following publication.

For all three journals, our results show that the share of US-affiliated authors of a paper has a negative effect on the number of citations this paper receives. For AER and JEEA papers, our measure for the co-author distance between editors and authors also shows that papers by 
authors at larger distances to editors receive significantly more citations. Moreover, additional binary connection measures show that AER and JEEA papers by authors with social ties to editors receive fewer citations in the years following publication.

Our results also indicate that there seems to be no methodological consensus between geographical regions on how to conduct economic experiments - or, equivalently, that there are different 'experimental schools'. Moreover, our results suggest that journal editors treat authors differently, not only with respect to their social ties but also based on authors' affiliations.

Our study provides important insights that editors can use in order to make their selection of research papers more efficient and fairer. Thus, we provide suggestions on how to increase impact factors and simultaneously further scientific progress.

The remainder of this paper is organized as follows. In Section $\underline{2}$, we describe the selection criteria for journals and papers, the data set, the ex ante quality proxies, and our measures for social ties. In Section $\underline{3}$, we compare how quality proxies and social tie measures differ between journals and between geographical regions before we test for editorial favoritism. In Section $\underline{4}$, we discuss the results, derive policy implications and conclude.

\section{Data Collection and Rationale for Variable Construction}

\subsection{Selection Criteria}

Although we are interested in the broad field of experimental economics, we decided to focus exclusively on papers that report results from laboratory experiments. Precisely, we focus on laboratory experiments that generate data in a controlled process using student participants who interact in an artificial environment ${ }^{1}$. In order to ensure the highest possible comparability, we do not consider papers that contain other types of experiments.

For laboratory experiments, objectively measurable proxies for an experiment's quality exist. Proxies for an experiment's quality are the total number of participants, the number of treatments, the number of participants per treatment, and the strength of monetary incentives (henceforth, strength of incentives). When conducting a laboratory experiment, the

\footnotetext{
${ }^{1}$ Our data contain papers where the majority of the participants were students. Papers where a large share of participants belonged to special groups (such as job professionals or caste members etc.) are not included in the data set.
} 
experimenter has full control over these characteristics. This is generally not the case for field experiments.

We chose the AER and the JEEA because they are general interest journals and the official journals of the American Economic Association and the European Economic Association, respectively. Moreover, the AER publishes the largest number of experimental papers among the top-5 economics journals (Nikiforakis and Slonim, 2019). We did not include any comments or papers from AER's Papers and Proceedings in the dataset. EE is the top field journal, and papers published there consist predominantly of laboratory experiments. We chose 1998 as the starting year for our analysis because EE was founded that year. EE is the specialized field journal of the Economic Science Association.

\subsection{Data Set}

Our data set contains 569 papers published between 1998 and 2018 (407 from EE, 121 from the AER, and 41 from the JEEA) ${ }^{2}$.

For each paper in our data set, we collected data on the:

- authors and their affiliations at the time of publication,

- number of female authors,

- number of citations received by each author in the five years before publication,

- total number of pages,

- total number of references, and

- $\quad$ paper's number of citations as of mid-November, 2020.

For all papers, we extracted data on the characteristics of the laboratory experiments reported in the papers. For each laboratory experiment we collected data on the:

- total number of participants,

- number of treatments,

- duration of the experiment,

- average earnings per participant,

- year in which the experiment was conducted, and

- place (laboratory) where the experiment was conducted.

\footnotetext{
${ }^{2}$ A full list of the included papers can be found in the supplementary material.
} 
In case a paper reported results from more than one laboratory experiment, we computed average values for the first four characteristics. Since not all papers report data on all characteristics, our data set contains some papers for which some or all of the experiment's characteristics are missing. In case of missing values, we tried to obtain the data from working paper versions or directly from the authors, which was successful in some cases. Citation data was obtained from Google Scholar (GS).

To identify connections between authors and editors, we collected the names and affiliations of all editors and co-editors for each of the three journals, as well as the years in which they served as editors or co-editors. Due to the time lag between submission and publication, we consider economists who served as editor or co-editor between 1996 and 2016.

We decided to focus on editors and co-editors and not on referees for three reasons. First, editors have the power to overrule referees' recommendations. Second, editors tend to select referees to whom they have easy access, implying that social ties between author and editor and between author and referee are correlated (Hamermesh, 1994). And third, data on referees is hard to obtain (an exception is Card et al., 2020).

\subsection{Proxies for the Quality of Laboratory Experiments}

Our quality proxies can be divided into ex ante and ex post proxies. Ex ante proxies are available before a paper is published and can thus be used by editors when deciding whether to reject or accept a paper. Ex post proxies measure the quality of a paper after it has been published.

The first two ex ante proxies are the total number of participants and the number of participants per treatment. Both are related to the experiment's statistical power. Experiments with higher power are more likely to detect small effects, tend to generate fewer false positives and, hence, produce results that are more likely to replicate. This in turn could increase confidence in the experiment's results. When designing their experiments, experimental economists often use simple rules of thumb, like those explained in List et al. (2011). However, Zhang and Ortmann (2013) show that many experiments are underpowered and that rules of thumb provide insufficient information about the power of a study. For detailed discussions of power analysis in experimental economics see Vasilaky and Brock (2020), Czibor et al. (2019), Ioannidis et al. (2017), Bellemare et al. (2016, 2014), and Zhang and Ortmann (2013).

For a given number of treatments, a larger total number of participants yields more observations which increases statistical power if statistical testing is carried out at the participant-level. The 
number of participants per treatment is a more suitable proxy for the experiment's power if an experiment contains a large number of treatments and if the statistical analysis involves a pairwise comparison of treatments. Arguably, another possibility is to consider the number of independent observations as a proxy for quality. However, what constitutes an independent observation is not clearly defined. Thus, we decided not to follow this approach (also see chapter 3 in Svorenčík and Maas, 2016).

The third ex ante proxy is the number of treatments. Ceteris paribus, a larger number of treatments increases quality because it allows to test more research hypotheses and/or to rule out more alternative explanations. Both increase quality, because tests of more hypotheses increase a paper's scientific contribution and ruling out more alternative hypotheses yields more credibility to the authors' claims.

The fourth proxy is the strength of incentives. According to the methodological literature on laboratory experiments, monetary incentives are related to the quality of an experiment because they tend to mitigate experimenter demand effects. Additionally, participants exert more effort in judgement and decision tasks, which reduces variance and the resulting data is less noisy (Bardsley et al., 2010; Camerer and Hogarth, 1999). The use of monetary incentives is an established methodological standard in economics (see Hertwig and Ortmann, 2001, 390) and all experiments in our data set use monetary incentives. We operationalized the strength of incentives by dividing a participant's average earnings (including the show-up fee) by the duration of the experiment (in minutes) and converting the result into real 2015 US-Dollars.

We focus on only one ex post proxy, namely citations ${ }^{3}$. This does not imply that citations reflect a paper's true quality. Rather, we decided to use the number of citations because data on citations is widely available and is heavily used (at least as a yardstick) to allocate positions and resources (Card et al., 2020; Card and DellaVigna, 2020; Hamermesh, 2018; Moed, 2006; Laband and Piette, 1994b). Moreover, assuming that editors seek to maximize their journals' impact factor, they have an incentive to accept papers that they expect to receive a high number of citations

\footnotetext{
${ }^{3}$ Other ex post proxies are being reprinted in anthologies, being discussed in canonical textbooks, or the amount of media-coverage.
} 


\subsection{Measures for Social Ties between Editors and Authors}

In the following, we introduce four different ways to measure social ties: the share of US authors, minDist (our novel measure based on co-authorship data), colleague connection, and co-author connection.

Between 1996 and 2016, the AER had 32 different editors, of which 31 (96.88\%) had their affiliation at US universities and one (3.12\%) in the UK. EE had eight different editors, of which five (62.5\%) had their affiliation at a US university and three (37.5\%) at a European university. The JEEA, founded in 2003, had 18 different editors, of which eight (44.44\%) had their affiliation at a US university and ten (55.56\%) at a European university. Given the high number of US-based editors, especially on the editorial board of the AER, we use the share of US authors for each paper as a first measure of social ties between editors and authors. Here we implicitly assume that a social tie is more likely to exist if editor and author have their affiliation within the same country (the US in case of the AER).

All previous studies on editorial favoritism use binary measures for social ties between editors and authors. For example, a social tie is assumed if editor and author had their affiliation at the same institution in the period of publication. We introduce a novel measure, which is based on co-authorship data. Specifically, we compiled a large dynamic network structure allowing us to compute all co-author distances between the 58 editors and the 931 authors in our data set at the time of publication of the respective paper. The calculation is based on approximately 450,000 unique papers published between 1950 and 2020 in 1,434 economics journals written by 268,000 authors. For each paper, we compute the distances between each author of the paper and all editors of the respective journal. Our novel measure, minDist, then is the minimum distance between all authors of a paper and all editors of the journal for the corresponding publication period. In line with Brogaard et al. (2014) we look at all editors of the respective journal two years before the paper was published. If no co-author connections could be identified between a single author (or between a group of authors) and the editors, we did not assign a value to minDist. These observations $(N=10)$ are not considered in the following results on minDist. Among the 586 papers for which we were able to calculate minDist, the values range from 0 to 9 (mean=4.53, $\mathrm{sd}=1.52$, median $\&$ mode $=5)$.

In addition to minDist, we use two commonly used binary measures of social ties. We assume a colleague connection if the author has the same affiliation at the time of publication like one of the editors of the respective journal two years before publication. A co-author connection exists if an author of the paper is also the editor of the journal (i.e. minDist $=0$ ), or if the author of the paper is a former co-author of one of the editors (minDist $=1$ ). 


\section{Results}

\subsection{How do Quality Proxies and Social Ties differ between Journals?}

The first five rows of Table 1 show mean values for quality proxies and social ties for the three journals and $p$-values from pairwise comparisons across journals. The total number of participants, and the number of treatments are significantly higher for the AER and the JEEA compared to EE (two-sided Mann-Whitney tests, all $p$-values $<0.05$ ). The variable strength of incentives is significantly higher for the AER compared to EE ( $p$-value $<0.01$ ). The strength of incentives could only be computed for $54 \%$ of AER papers, $72 \%$ of EE papers and $66 \%$ of JEEA papers. This is because, even in these prestigious journals, many papers do not report the number of participants, average earnings per participant, or the duration of the experiment. The means of citations per year do significantly differ between all three journals and are highest for the AER, followed by the JEEA.

Rows six to eight show mean values for social ties between authors and editors. In $10.74 \%$ of the AER papers and $17.07 \%$ of the JEEA papers, at least one author of the paper has a colleague-connection to one of the editors. These values are significantly higher than for EE (two-sided Fisher's exact tests, both $p$-values $<0.01$ ), where a colleague-connection is found for only $3.69 \%$ of the papers. The average values for minDist are also significantly lower for the AER and JEEA than for EE (two-sided Mann-Whitney tests, both $p$-values $<0.001$ ). 
TABLE 1. Quality Proxies and Social Tie Measures by Journal.

\begin{tabular}{|c|c|c|c|c|c|c|c|}
\hline $\begin{array}{l}\text { Row } \\
\# \\
\end{array}$ & & $\begin{array}{c}\text { AER } \\
(\mathrm{N}=121)\end{array}$ & $\begin{array}{c}\mathbf{E E} \\
(\mathrm{N}=\mathbf{4 0 7})\end{array}$ & $\begin{array}{c}\text { JEEA } \\
(\mathrm{N}=41)\end{array}$ & $\begin{array}{c}\text { AER vs. } \\
\text { EE }\end{array}$ & $\begin{array}{c}\text { AER vs. } \\
\text { JEEA }\end{array}$ & $\begin{array}{l}\text { EE vs. } \\
\text { JEEA }\end{array}$ \\
\hline & & \multicolumn{6}{|c|}{ Ex ante quality proxies } \\
\hline 1 & \# participants & $\begin{array}{c}273.78 \\
(\mathrm{~N}=114)\end{array}$ & $\begin{array}{c}194.83 \\
(\mathrm{~N}=404)\end{array}$ & $\begin{array}{l}284.58 \\
(\mathrm{~N}=40)\end{array}$ & $p<0.001$ & $p=0.396$ & $p<0.001$ \\
\hline 2 & \# treatments & $\begin{array}{c}4.70 \\
(\mathrm{~N}=120)\end{array}$ & $\begin{array}{c}3.91 \\
(\mathrm{~N}=404)\end{array}$ & $\begin{array}{c}4.74 \\
(\mathrm{~N}=35)\end{array}$ & $p=0.011$ & $p=0.538$ & $p=0.023$ \\
\hline 3 & $\begin{array}{l}\text { \# participants } \\
\text { per treatment }\end{array}$ & $\begin{array}{c}71.46 \\
(\mathrm{~N}=113)\end{array}$ & $\begin{array}{c}55.22 \\
(\mathrm{~N}=402)\end{array}$ & $\begin{array}{c}61.82 \\
(\mathrm{~N}=34)\end{array}$ & $p=0.266$ & $p=0.581$ & $p=0.202$ \\
\hline \multirow[t]{2}{*}{4} & $\begin{array}{l}\text { strength of } \\
\text { incentives }\end{array}$ & $\begin{array}{c}0.38 \\
(\mathrm{~N}=70)\end{array}$ & $\begin{array}{c}0.31 \\
(\mathrm{~N}=293)\end{array}$ & $\begin{array}{c}0.33 \\
(\mathrm{~N}=27)\end{array}$ & $p<0.001$ & $p=0.159$ & $p=0.482$ \\
\hline & & \multicolumn{6}{|c|}{ Ex post quality proxy } \\
\hline \multirow[t]{2}{*}{5} & $\begin{array}{l}\text { citations per } \\
\text { year }\end{array}$ & $\begin{array}{c}33.48 \\
(\mathrm{~N}=118) \\
\end{array}$ & $\begin{array}{c}6.50 \\
(\mathrm{~N}=342) \\
\end{array}$ & $\begin{array}{c}20.76 \\
(\mathrm{~N}=31) \\
\end{array}$ & $p<0.001$ & $p=0.015$ & $p<0.001$ \\
\hline & & \multicolumn{6}{|c|}{ Social Ties } \\
\hline 6 & $\begin{array}{l}\text { colleague } \\
\text { connection in } \%\end{array}$ & 10.74 & 3.69 & 17.07 & $p=0.005$ & $p=0.284$ & $p=0.002$ \\
\hline 7 & $\begin{array}{l}\text { co-author } \\
\text { connection in \% }\end{array}$ & 4.96 & 4.42 & 0.00 & $p=0.806$ & $p=0.338$ & $p=0.392$ \\
\hline 8 & $\begin{array}{l}\text { any connection } \\
\text { in } \%\end{array}$ & 14.05 & 7.37 & 17.07 & $p=0.029$ & $p=0.619$ & $p=0.065$ \\
\hline 9 & minDist & 3.98 & 4.76 & 3.93 & $p<0.001$ & $p=0.415$ & $p<0.001$ \\
\hline
\end{tabular}

Notes. Mean values and number of observations. For rows 1, 2, 3, 4, 5, and 9, the three right columns show the exact p-values for two-sided Mann-Whitney tests. For rows 6, 7, and 8, they show p-values for two-sided exact Fisher tests. For the calculation of citations per year we only include papers that were published before 2017.

\subsection{How do Quality Proxies and Social Ties differ between the US and Europe?}

In Table 2 , we look only at laboratory experiments conducted in the US or Europe. Slightly more than $82 \%$ of the laboratory experiments in our dataset were conducted in these two regions.

With respect to the total number of participants or the number of participants per treatment, there appear to be systematic differences between experiments conducted in both regions. Except for the JEEA, experiments conducted in Europe involve a significantly larger total number of participants. For all journals, European experiments have a significantly larger number of participants per treatment. With regard to the number of treatments and the strength of incentives, there are no significant differences between North-American and European experiments.

For the AER and EE we observe that laboratory experiments conducted in Europe receive significantly more citations per year compared to laboratory experiments conducted in the US. 
For colleague and co-author connections, we do not find significant differences between the US and Europe. However, we observe that for AER and EE papers the social tie measure minDist has significantly lower values for experiments conducted in the US.

TABLE 2. Quality Proxies and Social Tie Measures by Journal and Region.

\begin{tabular}{|c|c|c|c|c|c|c|c|}
\hline \multirow{3}{*}{$\begin{array}{l}\text { Row } \\
\#\end{array}$} & & \multicolumn{2}{|c|}{$\operatorname{AER}(\mathrm{N}=105)$} & \multicolumn{2}{|c|}{ EE $(N=324)$} & \multicolumn{2}{|c|}{ JEEA $(\mathrm{N}=38)$} \\
\hline & & \multicolumn{6}{|c|}{ Ex ante quality proxies } \\
\hline & & $\mathbf{U S}$ & Europe & US & Europe & US & Europe \\
\hline \multirow[t]{2}{*}{1} & \# participants & $\begin{array}{l}234.09 \\
(\mathrm{~N}=65)\end{array}$ & $\begin{array}{l}380.56 \\
(\mathrm{~N}=34)\end{array}$ & $\begin{array}{c}167.97 \\
(\mathrm{~N}=154)\end{array}$ & $\begin{array}{c}205.60 \\
(\mathrm{~N}=167)\end{array}$ & $\begin{array}{l}243.57 \\
(\mathrm{~N}=14)\end{array}$ & $\begin{array}{l}295.83 \\
(\mathrm{~N}=23)\end{array}$ \\
\hline & & \multicolumn{2}{|c|}{$p=0.002$} & \multicolumn{2}{|c|}{$p=0.010$} & \multicolumn{2}{|c|}{$p=0.957$} \\
\hline \multirow[t]{2}{*}{2} & \# treatments & $\begin{array}{c}4.61 \\
(\mathrm{~N}=69)\end{array}$ & $\begin{array}{c}5.00 \\
(\mathrm{~N}=35)\end{array}$ & $\begin{array}{c}3.86 \\
(\mathrm{~N}=155)\end{array}$ & $\begin{array}{c}3.81 \\
(\mathrm{~N}=166)\end{array}$ & $\begin{array}{c}5.00 \\
(\mathrm{~N}=12)\end{array}$ & $\begin{array}{c}4.48 \\
(\mathrm{~N}=21)\end{array}$ \\
\hline & & \multicolumn{2}{|c|}{$p=0.674$} & \multicolumn{2}{|c|}{$p=0.550$} & \multicolumn{2}{|c|}{$p=0.844$} \\
\hline \multirow[t]{2}{*}{3} & $\begin{array}{l}\text { \# part. per } \\
\text { treatment }\end{array}$ & $\begin{array}{c}55.24 \\
(\mathrm{~N}=64)\end{array}$ & $\begin{array}{l}113.70 \\
(\mathrm{~N}=34)\end{array}$ & $\begin{array}{c}49.68 \\
(\mathrm{~N}=153)\end{array}$ & $\begin{array}{c}59.90 \\
(\mathrm{~N}=166)\end{array}$ & $\begin{array}{c}37.90 \\
(\mathrm{~N}=11)\end{array}$ & $\begin{array}{c}73.53 \\
(\mathrm{~N}=21)\end{array}$ \\
\hline & & \multicolumn{2}{|c|}{$\mathrm{p}<0.001$} & \multicolumn{2}{|c|}{$p=0.007$} & \multicolumn{2}{|c|}{$p=0.012$} \\
\hline \multirow[t]{3}{*}{4} & $\begin{array}{l}\text { strength of } \\
\text { incentives }\end{array}$ & $\begin{array}{c}0.35 \\
(\mathrm{~N}=37) \\
\end{array}$ & $\begin{array}{c}0.45 \\
(\mathrm{~N}=28) \\
\end{array}$ & $\begin{array}{c}0.30 \\
(\mathrm{~N}=108) \\
\end{array}$ & $\begin{array}{c}0.33 \\
(\mathrm{~N}=130) \\
\end{array}$ & $\begin{array}{c}0.36 \\
(\mathrm{~N}=7) \\
\end{array}$ & $\begin{array}{c}0.31 \\
(\mathrm{~N}=18) \\
\end{array}$ \\
\hline & & \multicolumn{2}{|c|}{$p=0.050$} & \multicolumn{2}{|c|}{$p=0.082$} & \multicolumn{2}{|c|}{$p=0.745$} \\
\hline & & \multicolumn{6}{|c|}{ Ex post quality proxy } \\
\hline \multirow[t]{3}{*}{5} & $\begin{array}{l}\text { citations per } \\
\text { year }\end{array}$ & $\begin{array}{c}30.83 \\
(\mathrm{~N}=69) \\
\end{array}$ & $\begin{array}{c}44.85 \\
(\mathrm{~N}=33)\end{array}$ & $\begin{array}{c}5.47 \\
(\mathrm{~N}=136) \\
\end{array}$ & $\begin{array}{c}7.62 \\
(\mathrm{~N}=143) \\
\end{array}$ & $\begin{array}{c}20.52 \\
(\mathrm{~N}=12)\end{array}$ & $\begin{array}{c}21.30 \\
(\mathrm{~N}=17)\end{array}$ \\
\hline & & \multicolumn{2}{|c|}{$p=0.047$} & \multicolumn{2}{|c|}{$p=0.006$} & \multicolumn{2}{|c|}{$p=0.711$} \\
\hline & & \multicolumn{6}{|c|}{ Social Ties } \\
\hline \multirow[t]{2}{*}{6} & $\begin{array}{l}\text { colleague } \\
\text { connection in } \%\end{array}$ & 15.71 & 5.71 & 3.82 & 3.59 & 13.33 & 21.74 \\
\hline & & \multicolumn{2}{|c|}{$p=0.211$} & \multicolumn{2}{|c|}{$p=1.000$} & \multicolumn{2}{|c|}{$p=0.681$} \\
\hline \multirow[t]{2}{*}{7} & $\begin{array}{l}\text { co-author } \\
\text { connection in \% }\end{array}$ & 2.90 & 8.57 & 5.77 & 2.50 & 0.00 & 0.00 \\
\hline & & \multicolumn{2}{|c|}{0.332} & \multicolumn{2}{|c|}{0.166} & & \\
\hline 8 & any connection & 17.14 & 11.43 & 8.92 & 5.39 & 13.33 & 21.74 \\
\hline & & & & & & & \\
\hline 9 & minDist & 3.75 & 4.31 & 4.31 & 5.26 & 4.14 & 3.87 \\
\hline & & & & & & & \\
\hline
\end{tabular}

Notes. Mean values and number of observations. The rows below rows $1,2,3,4,5$, and 9 , show exact $p$-values for two-sided Mann-Whitney tests. The rows below rows 6, 7, and 8, show $p$-values for two-sided exact Fisher tests. For the calculation of citations per year we only include papers that were published before 2017 .

\subsection{Is there Evidence for Editorial Favoritism in Laboratory Experimental Economics?}

In the previous subsection, we saw that experiments conducted in Europe receive more citations than experiments conducted in the US. In this section, we investigate whether the differences in citations are mainly driven by differences in ex ante quality proxies or by social ties between authors and editors. Our ex ante proxies are scientific criteria because they are derived from methodological considerations (see section 2.3). Hence, we would expect them to influence the 
quality of a paper, which we proxy by the number of citations. Social ties, however, are nonscientific criteria, and if they have a negative effect on a paper's quality, this would constitute evidence of quality reducing editorial favoritism.

We start by looking at the relation between the inverse hyperbolic sine (asinh) ${ }^{4}$ of citations per year and minDist in Figure 1. For AER and JEEA papers, we see that there is a positive correlation between citations per year and minDist. Thus, Figure 1 shows how papers by authors at larger distances to editors receive a higher number of citations than papers written by authors with closer connections to the editors.
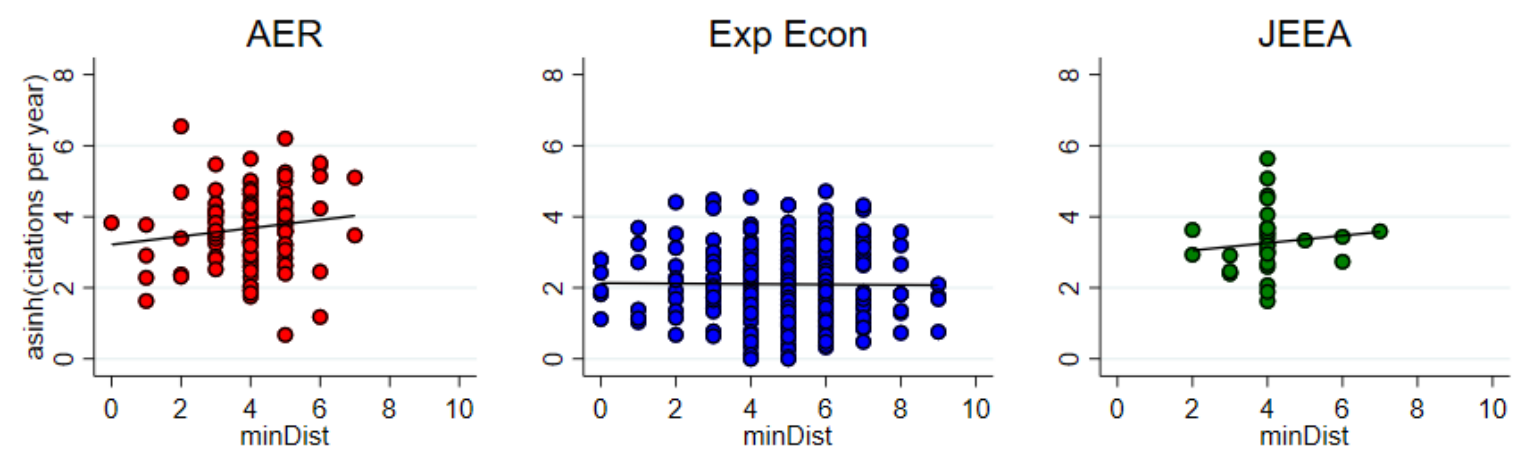

FIGURE 1. Scatterplots of minDist and asinh(citations per year) by journal.

Figure 1 is based on raw data, that is, we do not control for differences in ex ante quality characteristics and other factors, which might affect the number of citations a paper receives. Following Brogaard et al. (2014), Medoff (2003), and Laband and Piette (1994a) we estimate the following regression model:

$\operatorname{asinh}\left(C_{i}\right)=\beta_{0}+\beta_{1} A E R_{i}+\beta_{2} J E E A_{i}+\beta_{3} S T_{i}+\beta_{4}\left(S T_{i} * A E R_{i}\right)+\beta_{5}\left(S T_{i} * J E E A_{i}\right)+$ $\beta_{6} a g e_{i}+\gamma E_{i}+\delta P_{i}+\theta A_{i}+u_{i}$

The dependent variable $\operatorname{asinh}\left(C_{i}\right)$ is the inverse hyperbolic sine of the total number of citations a paper has received by mid-November, 2020. To ensure that each paper had sufficient time to receive citations, we only include papers that were published before 2017.

Our measure of social ties is $S T_{i}$. Dependent on the regression model it indicates either the relative share of US-affiliated authors, minDist, a colleague connection, a co-author connection or a combination of colleague- and co-author connection (any-connection) for paper $i$. Because

\footnotetext{
${ }^{4}$ In the following, we use the asinh transformation to account for 0 citations. This practice is in line with previous studies Card and DellaVigna (2020), Card et al. (2020), and Hengel and Moon (2020).
} 
the effect of social ties could differ between journals, we include interaction terms for the respective social tie measure and indicator variables for journals.

We control for each paper's age, as well as for several other characteristics that might affect the number of citations. $E_{i}$ is a vector containing the ex ante quality proxies of the experiments reported in paper $i$. By including indicator variables for journals, we control for journal fixed effects. The vector $P_{i}$ contains controls for number of (EE-equivalent) pages, number of references, and the JEL-classification. $A_{i}$ is a vector containing author related controls for gender (share of female authors), reputation (average of citations received in the five years prior publication), and number of authors.

Table $\underline{3}$ shows estimation results for different OLS regression models with standard errors clustered by journal (for full results see, appendix Tables $\underline{5}$ and $\underline{6}$ ). In Panel A, we examine the influence of the share of US authors (models 1 to 3 ) and colleague connections (models 4 to 6). The results show that, for all three journals, the share of US authors has a negative effect on the number of citations. In models 1 and 2, this effect is even stronger for AER and JEEA papers. For EE papers, the results of models 4 to 6 indicate that colleague connections have a significant positive effect on citations. In contrast, for AER and JEEA papers we observe significantly negative effects of colleague connections.

In the lower half of Table $\underline{3}$ (Panel B), we examine the effect of the minimum co-authorship distance (minDist) and a direct authorship or co-authorship (co-author connection, minDist $<2$ ) on the number of citations. We observe significant positive effects for the interaction terms of minDist with AER or JEEA. This implies that papers by authors at longer distances receive significantly more citations than papers by authors with closer connections to the editors. For the AER, this effect is also apparent when we consider direct co-author connections. AER papers written by the editors themselves or by their co-authors have a significantly lower number of citations. When we use the raw number of citations as dependent variable (see, appendix Table 11), the results show that a one point increase in minDist for AER papers is associated with an increase between 116 and 133 citations.

The variable colleague connection is significantly positive in all three models in Panel A. The variable co-author connection is also significantly positive in model 4 of panel B. This could imply that EE editors use their professional connections to identify high quality papers for their journal. 
Among the ex ante quality proxies, only the number of treatments and the strength of incentives have significant positive effects on citations in several models (see Tables $\underline{5}$ to $\underline{12}$ in the appendix).

Table 3. Impact of Social Ties on Ex Post Paper Quality.

\begin{tabular}{|c|c|c|c|c|c|c|}
\hline \multicolumn{7}{|c|}{$\begin{array}{l}\text { Panel A } \\
\text { social ties: share of US authors and colleague-connected papers }\end{array}$} \\
\hline & \multicolumn{6}{|c|}{ dependent variable: asinh(GS citations) } \\
\hline & (1) & (2) & (3) & (4) & $(5)$ & (6) \\
\hline share US authors & $\begin{array}{c}-0.16^{* * *} \\
(0.01)\end{array}$ & $\begin{array}{c}-0.12^{* * * *} \\
(0.01)\end{array}$ & $\begin{array}{c}-0.13^{* * *} \\
(0.01)\end{array}$ & & & \\
\hline share US auth. * AER & $\begin{array}{c}-0.41^{* * * *} \\
(0.00)\end{array}$ & $\begin{array}{c}-0.27^{* *} \\
(0.04)\end{array}$ & $\begin{array}{l}-0.11 \\
(0.12)\end{array}$ & & & \\
\hline share US auth. * JEEA & $\begin{array}{c}-0.14^{* * *} \\
(0.00)\end{array}$ & $\begin{array}{c}-0.33^{* *} \\
(0.03)\end{array}$ & $\begin{array}{c}0.04 \\
(0.22)\end{array}$ & & & \\
\hline colleague con. & & & & $\begin{array}{c}0.40^{* * *} \\
(0.00)\end{array}$ & $\begin{array}{c}0.36^{* * *} \\
(0.01)\end{array}$ & $\begin{array}{l}0.14^{* *} \\
(0.03)\end{array}$ \\
\hline colleague con. $*$ AER & & & & $\begin{array}{c}-0.64^{* * *} \\
(0.01)\end{array}$ & $\begin{array}{c}-0.51^{* * * *} \\
(0.02)\end{array}$ & $\begin{array}{l}-0.25 \\
(0.14)\end{array}$ \\
\hline colleague con. * JEEA & & & & $\begin{array}{c}-0.69^{* * *} \\
(0.01)\end{array}$ & $\begin{array}{c}-0.63^{* * *} \\
(0.04)\end{array}$ & $\begin{array}{c}-1.06^{* * *} \\
(0.08)\end{array}$ \\
\hline $\mathrm{E}$ & No & Yes & Yes & No & Yes & Yes \\
\hline $\mathrm{P}$ & No & No & Yes & No & No & Yes \\
\hline A & No & No & Yes & No & No & Yes \\
\hline $\mathrm{N}$ & 329 & 327 & 318 & 329 & 327 & 318 \\
\hline Adjusted $\mathrm{R}^{2}$ & 0.41 & 0.41 & 0.49 & 0.40 & 0.41 & 0.49 \\
\hline \multicolumn{7}{|l|}{ Panel B } \\
\hline \multicolumn{7}{|c|}{ social ties: minDist and coauthor-connected papers } \\
\hline & \multicolumn{6}{|c|}{ dependent variable: asinh(GS citations) } \\
\hline & $(1)$ & $(2)$ & $(3)$ & $(4)$ & $(5)$ & $(6)$ \\
\hline minDist & $\begin{array}{l}-0.01^{* * *} \\
(0.00)\end{array}$ & $\begin{array}{l}-0.01 \\
(0.00)\end{array}$ & $\begin{array}{l}-0.01 \\
(0.00)\end{array}$ & & & \\
\hline minDist * AER & $\begin{array}{l}0.33^{* * *} \\
(0.00)\end{array}$ & $\begin{array}{l}0.33^{* * *} \\
(0.01)\end{array}$ & $\begin{array}{l}0.22^{*} \\
(0.05)\end{array}$ & & & \\
\hline $\operatorname{minDist} *$ JEEA & $\begin{array}{l}0.14^{* * *} \\
(0.00)\end{array}$ & $\begin{array}{l}0.15^{* * *} \\
(0.01)\end{array}$ & $\begin{array}{l}0.24^{* * *} \\
(0.02)\end{array}$ & & & \\
\hline co-author connnection & & & & $\begin{array}{c}0.06^{* * *} \\
(0.01)\end{array}$ & $\begin{array}{l}-0.01 \\
(0.03)\end{array}$ & $\begin{array}{c}0.14 \\
(0.05)\end{array}$ \\
\hline co-aut. con. * AER & & & & $\begin{array}{c}-0.86^{* * *} \\
(0.01)\end{array}$ & $\begin{array}{l}-0.92^{* * *} \\
(0.06)\end{array}$ & $\begin{array}{c}-0.87^{* *} \\
(0.20)\end{array}$ \\
\hline co-aut. con. * JEEA & & & & n.a. & n.a. & n.a. \\
\hline $\mathrm{E}$ & No & Yes & Yes & No & Yes & Yes \\
\hline $\mathrm{P}$ & No & No & Yes & No & No & Yes \\
\hline A & No & No & Yes & No & No & Yes \\
\hline $\mathrm{N}$ & 321 & 319 & 310 & 321 & 319 & 310 \\
\hline Adjusted $\mathrm{R}^{2}$ & 0.41 & 0.42 & 0.49 & 0.40 & 0.41 & 0.48 \\
\hline
\end{tabular}

Notes. OLS regressions with standard errors clustered by journal in parentheses: ${ }^{*} \mathrm{p}<0.10,{ }^{* *} \mathrm{p}<0.05,{ }^{* * *} \mathrm{p}<$ 0.01 . Each regression model includes controls for journal and years since publication.

At least for the share of US authors, the results of Table $\underline{3}$ may at least partially be driven by network effects. In 2018, more than half (57.84\%) of all experimental economists on the RePEc list $(N=1,831)$ of authors in experimental economics had a European affiliation, followed by economists with an affiliation in North America (30.20\%), Asia (5.90\%), Australia or New 
Zealand (3.82\%), South America (1.86\%), and Africa (0.38\%). In the following, we therefore examine whether our results change when we consider solely US papers.

Table 4 shows the results for regressions exclusively including papers with experiments conducted in the US and where the share of US affiliated authors is at least 0.5 (for full results see, appendix Table 7). In models 1 and 2, the variable minDist again has a significant positive effect on the number of citations for AER and JEEA papers. Due to the small number of observations, we combined the variables colleague connection and co-author connection into the variable any connection. In models 4 and 5, we observe that AER papers by authors with connections to the editors receive significantly fewer citations.

Table 4. Impact of Social Ties on Ex Post Paper Quality (only US papers).

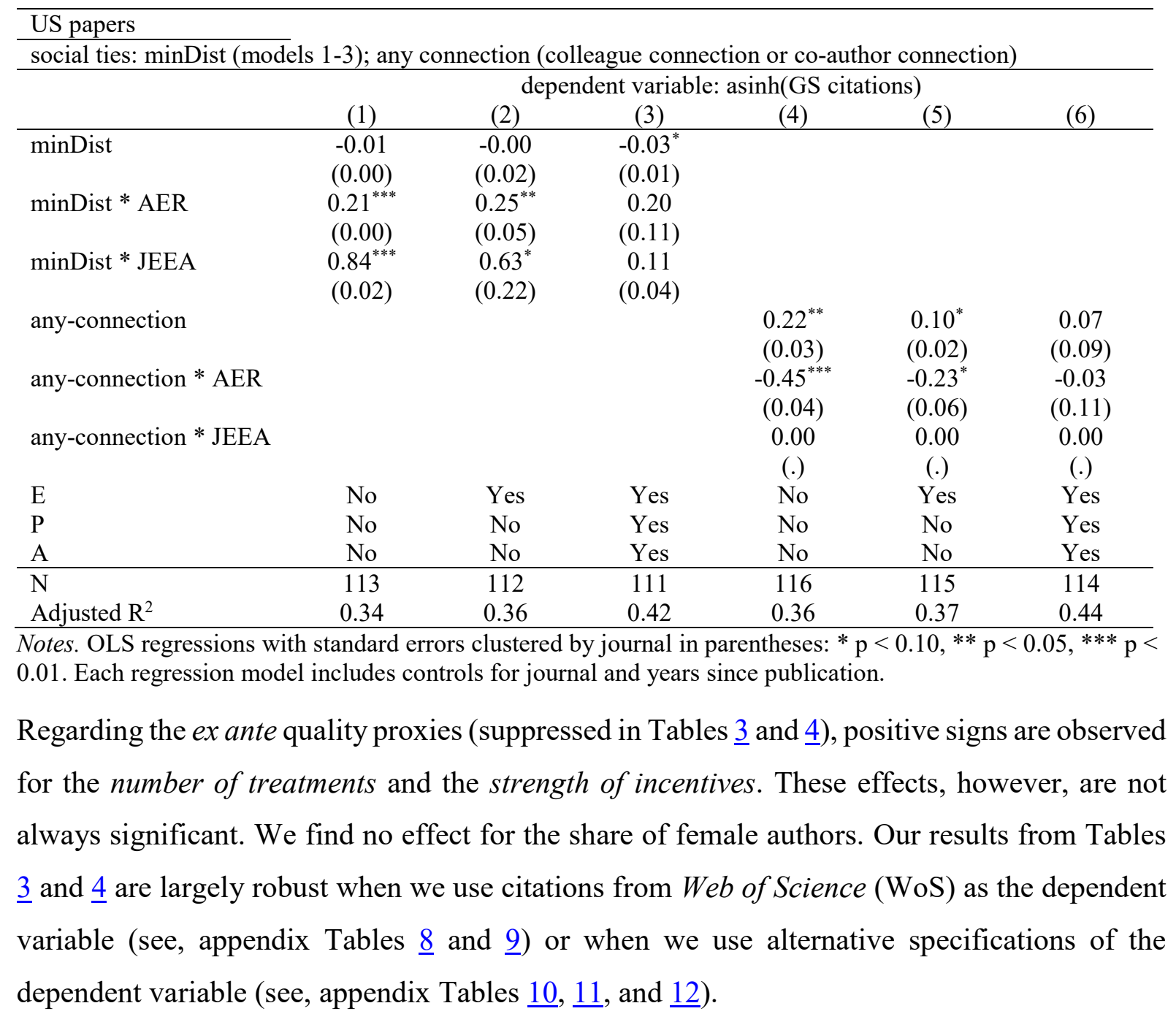




\section{Discussion and Conclusion}

In this paper we use a novel data set containing data on all laboratory experiments published in the $A E R, \mathrm{EE}$ and the JEEA from 1998 to 2018. We identify and compare several objectively measurable quality proxies between journals and between the US and Europe and test for editorial favoritism. Our study adds several aspects to the existing literature on editorial favoritism.

First, focusing on one particular field allows us to look not only at citations as an ex post quality proxy, but also to analyze how various ex ante quality proxies which are available only for laboratory experiments (total number of participants, participants per treatment, number of treatments, strength of incentives) differ between journals and regions (which may follow different methodological traditions). Second, we conduct an empirical analysis on the role of the above-mentioned quality characteristics and social ties between authors and editors. In this context we introduce minDist, a new measure for social ties which is based on the co-authorship distance between authors and editors. In contrast to existing binary measures of social ties, minDist is more fine-grained since it allows to capture indirect co-author connections between editors and authors. In our calculation of $\operatorname{minDist}$ we also considered significantly more journals than previous studies used to identify co-author connections. Thus, the use of minDist allows us to investigate the effects of (co-author based) social ties also cases like the JEEA where no direct co-author connections exist between editors and authors (see Table $\underline{3}$ ). Nevertheless, minDist also has limitations. For one, it is not straightforward how to interpret large minDist values: is the co-author of your co-author's co-author's co-author still someone you would favor? For the other, we considered all co-authorship connections in the calculation of minDist and did not impose any restriction on the time span. As a result, several minDist values may be based on co-authorship connections that lie relatively far in the past. However, a restriction of the time span would require a definition of when a connection should be classified as expired. Since such a definition would necessarily be arbitrary, we did not impose a restriction.

Our results show that various ex ante quality proxies are higher for AER and JEEA papers than for EE papers. This also reflects the higher number of citations per year that papers published in the former two journals received. Comparing experiments conducted in the US and Europe, there are no differences regarding the number of treatments and no or only small differences regarding the strength of incentives. However, European experiments published in the AER and EE rely on a significantly larger total number of participants and in all three journals on a 
significantly larger number of participants per treatment. This difference is most pronounced for the AER where, on average, experiments conducted in the US have 55 participants per treatment while experiments conducted in Europe have 113 participants per treatment.

The differences in the total number of participants and participants per treatment could reflect different methodological standards. However, they could also indicate substantial barriers to entry for European economists, especially for the AER, where US-dominance is more pronounced in the composition of the editorial board. Our results for the total number of participants and the strength of incentives imply that experimental economists from Europe pay a higher price for publishing their papers, compared to experimental economists from the US. However, our data cannot answer if this is due to barriers of entry or due to economists in Europe having easier access to research funding compared to their colleagues in the $\mathrm{US}^{5}$.

Different measures of social ties show that there are closer social ties between authors and editors for AER and JEEA papers than there are for EE papers. A potential explanation for this result is that the number of EE editors during the respective period was significantly smaller than the number of editors in the other two journals.

Our investigation of editorial favoritism shows that the share of US authors in the top general interest journals AER and JEEA has a significant negative effect on the number of citations a paper received. For AER and JEEA papers, several measures of social ties indicate that papers by authors with social ties or closer connections to the editors are of lower quality than papers without these social ties.

These differences can be interpreted as indirect evidence of discrimination, indicating that a paper from an author with social ties is accepted for publication despite a higher-quality paper from an author without social ties being available. Of course, this only holds true if high-quality papers by authors without social ties to the editorial board were submitted and rejected.

\footnotetext{
${ }^{5}$ We thank Gary Charness for drawing our attention to this aspect. Unfortunately, there are no data on the amount of research funding for experimental economists in different regions. However, we consider it unlikely that there is a causal relationship between the availability of research funding and the average total number of participants. Even if research funds were more readily available in Europe, they could be used, for example, to conduct more (single) projects.
} 
However, given the high rejection rates of the AER and the JEEA, we think that this is quite plausible ${ }^{6}$.

Note, however, that our results do not imply that editors consciously discriminate against authors from outside the US or against authors at longer co-authorship distances to themselves. Rather, it is possible that editors systematically fail to predict the number of citations a paper will receive in the years following its publication (i.e., editors might wrongly predict that papers authored by US-based and/or connected authors receive more citations than they actually do). Nonetheless, if citations can be taken as a proxy for quality, this will slow down scientific progress, and editors will fail to maximize their journal's impact factor.

Except for the share of US authors, we find no negative or significantly positive effects of social ties for EE papers. This might be explained by the fact that EE is a field journal. EE editors usually have an in-depth expertise in experimental economics and may thus be particularly well qualified to identify high quality experimental papers. Editors of the AER and the JEEA do not necessarily have expertise in experimental economics. While experimental papers are certainly reviewed by referees with an expertise in experimental economics also in these general interest journals, review processes are only initiated if the papers have not been desk-rejected immediately. In order to avoid that potentially promising high quality papers are mistakenly desk-rejected, thus, editors whose expertise only partly matches the method used in a submitted paper could intensify their efforts to obtain second opinions from colleagues who are more competent with regard to this method.

We hope that our results raise an awareness of potential biases in the editorial process among editorial boards and that these biases will thereby be reduced in the longer term. Journals could facilitate further research on editorial favoritism (and discriminating editorial practices in general) by regularly publishing not only numbers on submissions, desk-rejections, revise and resubmit decisions, etc., but also on which countries or institutions the submissions came from. In this context, it would also be useful to report the gender distribution of authors for submissions. By comparing published papers with all submissions, future studies could investigate whether authors from certain countries, from certain institutions, or of a certain gender are over- or under-represented in the published papers. Moreover, in their selection of

\footnotetext{
${ }^{6}$ In 2019, for example, only $6.95 \%$ of all submissions $(\mathrm{N}=1,927)$ were accepted at the AER (Duflo 2020). The JEEA received 1,252 submissions between Q4 2019 and Q3 2020 and desk-rejected 60\% of these papers (Source: Tweet by Imran Rasul on January 6, 2021).
} 
new editors and associate editors, editorial board members could pay explicit attention not only to gender fairness but also to geographical diversity (Palser et al., 2021; Angus et al., 2020). 


\section{References}

Angus, S.D., Atalay, K., Newton, J. and Ubilava, D. (2020). "Geographic Diversity in Economic Publishing." Available at SSRN.

Bardsley, N., Cubitt, R., Loomes, G., Moffatt, P., Starmer, C. and Sugden R. (2010). Experimental Economics - Rethinking the Rules. Princeton University Press.

Bellemare, C., Bissonnette, L. and Kröger S. (2014). "Statistical power of within and between-subjects designs in economic experiments." IZA Discussion Paper No. 8583.

Bellemare, C., Bissonnette, L. and Kröger S. (2016). "Simulating power of economic experiments: the powerBBK package." Journal of the Economic Science Association, 2(2), 157-168.

Brogaard, J., Engelberg, J. and Parsons, C.A. (2014). "Networks and productivity: Causal evidence from editor rotations." Journal of Financial Economics, 111(1), 251-270.

Camerer, C.F. and Hogarth, R.M. (1999). "The effects of financial incentives in experiments: A review and capital-labor-production framework." Journal of Risk and Uncertainty, 19(1-3), $7-42$.

Card, D. and DellaVigna, S. (2020). "What do editors maximize? Evidence from four economics journals." Review of Economics and Statistics, 102(1), 195-217.

Card, D., DellaVigna, S., Funk, P. and Iriberri, N. (2020). "Are referees and editors in economics gender neutral?." The Quarterly Journal of Economics, 135(1), 269-327.

Colussi, T. (2018). "Social ties in academia: A friend is a treasure." Review of Economics and Statistics, 100(1), 45-50.

Czibor, E., Jimenez-Gomez, D. and List, J. A. (2019). "The dozen things experimental economists should do (more of)." Southern Economic Journal, 86(2), 371-432.

Duflo, E. (2020). "Report of the Editor: American Economic Review." AEA Papers and Proceedings, 110, 660-74.

Hamermesh, D.S. (1994). "Facts and myths about refereeing." Journal of Economic Perspectives, 8(1), 153-163.

Hamermesh, D.S. (2018). "Citations in economics: Measurement, uses, and impacts." Journal of Economic Literature, 56(1), 115-56.

Hengel, E. and Moon, E. (2020). "Gender and quality at top economics journals." Working Paper, University of Liverpool, UK.

Hertwig, R. and Ortmann, A. (2001). "Experimental practices in economics: A methodological challenge for psychologists?." Behavioral and Brain Sciences, 24(3), 383403.

Ioannidis, J.P.A., Stanley, T.D. and Doucouliagos, H. (2017). "The power of bias in economics research." The Economic Journal, 127(605), 236-265. 
Laband, D.N. and Piette, M.J. (1994). "Favoritism versus search for good papers: Empirical evidence regarding the behavior of journal editors." Journal of Political Economy, 102(1), 194-203.

Laband, D.N. and Piette, M.J. (1994b). "The relative impacts of economics journals: 19701990." Journal of Economic Literature, 32(2), 640-666.

List, J.A., Sadoff, S. and Wagner, M. (2011). "So you want to run an experiment, now what? Some simple rules of thumb for optimal experimental design." Experimental Economics, 14(4), 439.

Medoff, M.H. (2003). "Editorial favoritism in economics?." Southern Economic Journal (2003): 425-434.

Moed, H.F. (2006). Citation analysis in research evaluation. Vol. 9. Springer Science \& Business Media.

Nikiforakis, N. and Slonim, R. (2019). "Editors' Preface: Trends in experimental economics (1975-2018)." Journal of the Economic Science Association, 5, 1-6.

Palser, E.R., Lazerwitz, M. and Fotopoulou, K. (2021). "Gender and geographical disparity in editorial boards of journals in psychology and neuroscience." bioRxiv.

Svorenčík, A. and Maas, H. (2016). The making of experimental economics: Witness seminar on the emergence of a field. Springer.

Vasilaky, K.N. and Brock, J.M. (2020). "Power(ful) guidelines for experimental economists." Journal of the Economic Science Association, 6(2), 189-212.

Zhang, L. and Ortmann, A. (2013). "Exploring the meaning of significance in experimental economics." UNSW Australian School of Business Research Paper 2013-32. 


\section{Appendix}

Table 5. Impact of Social Ties on Paper Quality (Full Results I).

\begin{tabular}{|c|c|c|c|c|c|c|}
\hline & \multicolumn{6}{|c|}{ dependent variable: asinh(GS citations) } \\
\hline & (1) & (2) & (3) & (4) & (5) & (6) \\
\hline \multirow[t]{2}{*}{ AER } & $1.87^{* * *}$ & $1.72^{* * *}$ & $1.71^{* * *}$ & $1.66^{* * *}$ & $1.57^{* * *}$ & $1.63^{* * *}$ \\
\hline & $(0.00)$ & $(0.05)$ & $(0.07)$ & $(0.01)$ & $(0.02)$ & $(0.09)$ \\
\hline \multirow[t]{2}{*}{ JEEA } & $1.18^{* * *}$ & $1.22^{* * *}$ & $0.95^{* *}$ & $1.21^{* * *}$ & $1.15^{* * *}$ & $1.11^{* * *}$ \\
\hline & $(0.00)$ & $(0.03)$ & $(0.14)$ & $(0.00)$ & $(0.00)$ & $(0.02)$ \\
\hline \multirow[t]{2}{*}{ share US auth. } & $-0.16^{* * *}$ & $-0.12^{* * *}$ & $-0.13^{* * *}$ & & & \\
\hline & $(0.01)$ & $(0.01)$ & $(0.01)$ & & & \\
\hline \multirow[t]{2}{*}{ share US auth. * AER } & $-0.41^{* * *}$ & $-0.27^{* *}$ & -0.11 & & & \\
\hline & $(0.00)$ & $(0.04)$ & $(0.12)$ & & & \\
\hline \multirow[t]{2}{*}{ share US auth. * JEEA } & $-0.14^{* * *}$ & $-0.33^{* *}$ & 0.04 & & & \\
\hline & $(0.00)$ & $(0.03)$ & $(0.22)$ & & & \\
\hline colleague con. & & & & $\begin{array}{c}0.40^{* * *} \\
(0.00)\end{array}$ & $\begin{array}{c}0.36^{* * *} \\
(0.01)\end{array}$ & $\begin{array}{l}0.14^{* *} \\
(0.03)\end{array}$ \\
\hline \multirow[t]{2}{*}{ colleague con. * AER } & & & & $-0.64^{* * *}$ & $-0.51^{* * *}$ & -0.25 \\
\hline & & & & $(0.01)$ & $(0.02)$ & $(0.14)$ \\
\hline \multirow[t]{2}{*}{ colleague con. * JEEA } & & & & $-0.69^{* * *}$ & $-0.63^{* * *}$ & $-1.06^{* * *}$ \\
\hline & & & & $(0.01)$ & $(0.04)$ & $(0.08)$ \\
\hline \multirow{2}{*}{ age } & $0.09^{* * *}$ & $0.09^{* * *}$ & $0.10^{* * *}$ & $0.08^{* * *}$ & $0.09^{* * *}$ & $0.10^{* * *}$ \\
\hline & $(0.00)$ & $(0.00)$ & $(0.01)$ & $(0.00)$ & $(0.00)$ & $(0.01)$ \\
\hline \multirow[t]{2}{*}{ part. per treatment } & & 0.00 & 0.00 & & 0.00 & 0.00 \\
\hline & & $(0.00)$ & $(0.00)$ & & $(0.00)$ & $(0.00)$ \\
\hline \multirow[t]{2}{*}{ treatments } & & $0.04^{* *}$ & 0.04 & & $0.04^{* * *}$ & 0.04 \\
\hline & & $(0.01)$ & $(0.02)$ & & $(0.00)$ & $(0.02)$ \\
\hline \multirow[t]{2}{*}{ strength of incentives } & & $0.57^{*}$ & 0.47 & & $0.61^{*}$ & 0.49 \\
\hline & & $(0.14)$ & $(0.21)$ & & $(0.20)$ & $(0.25)$ \\
\hline \multirow[t]{2}{*}{ pages (EE-equivalent) } & & & -0.02 & & & -0.02 \\
\hline & & & $(0.02)$ & & & $(0.02)$ \\
\hline \multirow[t]{2}{*}{ references } & & & 0.01 & & & 0.02 \\
\hline & & & $(0.01)$ & & & $(0.01)$ \\
\hline JEL-micro & & & -0.08 & & & -0.07 \\
\hline & & & $(0.17)$ & & & $(0.17)$ \\
\hline JEL-theory & & & -0.38 & & & $-0.40^{*}$ \\
\hline & & & $(0.15)$ & & & $(0.12)$ \\
\hline JEL-labor & & & -0.14 & & & -0.11 \\
\hline & & & $(0.31)$ & & & $(0.28)$ \\
\hline JEL-econometrics & & & $-0.81^{* *}$ & & & $-0.78^{* *}$ \\
\hline & & & $(0.15)$ & & & $(0.15)$ \\
\hline JEL-industrial & & & $-1.51^{* *}$ & & & $-1.58^{* * *}$ \\
\hline & & & $(0.18)$ & & & $(0.15)$ \\
\hline JEL-international & & & $-4.72^{* * *}$ & & & $-4.65^{* * *}$ \\
\hline & & & $(0.44)$ & & & $(0.39)$ \\
\hline JEL-finance & & & $-1.08^{* * *}$ & & & $-1.03^{* * *}$ \\
\hline & & & $(0.08)$ & & & $(0.07)$ \\
\hline JEL-public & & & $0.94^{*}$ & & & 0.94 \\
\hline & & & $(0.29)$ & & & $(0.33)$ \\
\hline JEL-health & & & -1.61 & & & -1.65 \\
\hline & & & $(0.65)$ & & & $(0.58)$ \\
\hline JEL-development & & & -0.59 & & & -0.46 \\
\hline & & & $(0.38)$ & & & $(0.30)$ \\
\hline JEL-other & & & 0.08 & & & 0.02 \\
\hline & & & $(0.40)$ & & & $(0.39)$ \\
\hline share fem. auth. & & & 0.10 & & & 0.08 \\
\hline & & & $(0.19)$ & & & $(0.19)$ \\
\hline reputation & & & 0.00 & & & $0.00^{* *}$ \\
\hline & & & $(0.00)$ & & & $(0.00)$ \\
\hline number of auth. & & & -0.05 & & & -0.04 \\
\hline & & & $(0.05)$ & & & $(0.05)$ \\
\hline Constant & $3.40^{* * *}$ & $3.01^{* * *}$ & $3.05^{* * *}$ & $3.38^{* * *}$ & $2.94^{* * *}$ & $2.98^{* * *}$ \\
\hline & $(0.03)$ & $(0.04)$ & $(0.11)$ & $(0.04)$ & $(0.03)$ & $(0.12)$ \\
\hline $\mathrm{N}$ & 329 & 327 & 318 & 329 & 327 & 318 \\
\hline Adjusted $\mathrm{R}^{2}$ & 0.41 & 0.41 & 0.49 & 0.40 & 0.41 & 0.49 \\
\hline
\end{tabular}

Notes. OLS regressions with standard errors clustered by journal in parentheses: $* \mathrm{p}<0.10,{ }^{* *} \mathrm{p}<0.05,{ }^{* * *} \mathrm{p}<$ 0.01 . 
Table 6. Impact of Social Ties on Paper Quality (Full Results II).

\begin{tabular}{|c|c|c|c|c|c|c|}
\hline & \multicolumn{6}{|c|}{ dependent variable: asinh(GS citations) } \\
\hline & (1) & $(2)$ & (3) & (4) & $(5)$ & $(6)$ \\
\hline \multirow[t]{2}{*}{ AER } & $0.28^{* * *}$ & $0.16^{* *}$ & 0.71 & $1.67^{* * *}$ & $1.58^{* * *}$ & $1.66^{* * *}$ \\
\hline & $(0.00)$ & $(0.03)$ & $(0.29)$ & $(0.01)$ & $(0.02)$ & $(0.08)$ \\
\hline \multirow[t]{2}{*}{ JEEA } & $0.54^{* * *}$ & $0.44^{* *}$ & -0.12 & $1.10^{* * *}$ & $1.06^{* * *}$ & $0.91^{* * *}$ \\
\hline & $(0.02)$ & $(0.07)$ & $(0.10)$ & $(0.00)$ & $(0.01)$ & $(0.04)$ \\
\hline \multirow[t]{2}{*}{$\operatorname{minDist}$} & $-0.01^{* * *}$ & -0.01 & -0.01 & & & \\
\hline & $(0.00)$ & $(0.00)$ & $(0.00)$ & & & \\
\hline \multirow[t]{2}{*}{ minDist * AER } & $0.33^{* * *}$ & $0.33^{* * *}$ & $0.22^{*}$ & & & \\
\hline & $(0.00)$ & $(0.01)$ & $(0.05)$ & & & \\
\hline \multirow[t]{2}{*}{$\operatorname{minDist} *$ JEEA } & $0.14^{* * *}$ & $0.15^{* * *}$ & $0.24^{* * *}$ & & & \\
\hline & $(0.00)$ & $(0.01)$ & $(0.02)$ & & & \\
\hline \multirow[t]{2}{*}{ co-aut. con. } & & & & $0.06^{* * *}$ & -0.01 & 0.14 \\
\hline & & & & $(0.01)$ & $(0.03)$ & $(0.05)$ \\
\hline \multirow[t]{2}{*}{ co-aut. con. * AER } & & & & $-0.86^{* * *}$ & $-0.92^{* * * *}$ & $-0.87^{* *}$ \\
\hline & & & & $(0.01)$ & $(0.06)$ & $(0.20)$ \\
\hline \multirow[t]{2}{*}{ co-aut. con. * JEEA } & & & & 0.00 & 0.00 & 0.00 \\
\hline & & & & (.) & $()$. & (.) \\
\hline \multirow{2}{*}{ age } & $0.08^{* * *}$ & $0.08^{* *}$ & $0.10^{* *}$ & $0.08^{* * *}$ & $0.08^{* * *}$ & $0.10^{* *}$ \\
\hline & $(0.01)$ & $(0.01)$ & $(0.01)$ & $(0.00)$ & $(0.01)$ & $(0.01)$ \\
\hline \multirow{2}{*}{ part. per treatment } & & 0.00 & 0.00 & & 0.00 & 0.00 \\
\hline & & $(0.00)$ & $(0.00)$ & & $(0.00)$ & $(0.00)$ \\
\hline \multirow[t]{2}{*}{ treatments } & & $0.04^{* *}$ & 0.04 & & $0.04^{* * * *}$ & 0.04 \\
\hline & & $(0.00)$ & $(0.02)$ & & $(0.00)$ & $(0.02)$ \\
\hline \multirow[t]{2}{*}{ strength of incentives } & & 0.74 & 0.54 & & 0.70 & 0.54 \\
\hline & & $(0.32)$ & $(0.34)$ & & $(0.28)$ & $(0.34)$ \\
\hline \multirow[t]{2}{*}{ pages (EE-equivalent) } & & & -0.02 & & & -0.02 \\
\hline & & & $(0.02)$ & & & $(0.02)$ \\
\hline \multirow[t]{2}{*}{ references } & & & 0.01 & & & 0.02 \\
\hline & & & $(0.01)$ & & & $(0.01)$ \\
\hline JEL-micro & & & -0.08 & & & -0.09 \\
\hline & & & $(0.19)$ & & & $(0.19)$ \\
\hline JEL-theory & & & -0.40 & & & -0.42 \\
\hline & & & $(0.17)$ & & & $(0.16)$ \\
\hline JEL-labor & & & $-0.34^{*}$ & & & $-0.37^{*}$ \\
\hline & & & $(0.11)$ & & & $(0.12)$ \\
\hline JEL-econometrics & & & $-0.79^{* *}$ & & & $-0.81^{* *}$ \\
\hline & & & $(0.17)$ & & & $(0.16)$ \\
\hline JEL-industrial & & & $-1.47^{* *}$ & & & $-1.53^{* * *}$ \\
\hline & & & $(0.15)$ & & & $(0.14)$ \\
\hline JEL-international & & & $-5.62^{* * *}$ & & & $-5.87^{* * *}$ \\
\hline & & & $(0.25)$ & & & $(0.05)$ \\
\hline JEL-finance & & & $-1.11^{* * *}$ & & & $-1.08^{* * *}$ \\
\hline & & & $(0.03)$ & & & $(0.03)$ \\
\hline JEL-public & & & $0.89^{*}$ & & & 0.99 \\
\hline & & & $(0.27)$ & & & $(0.36)$ \\
\hline JEL-health & & & $-1.58^{*}$ & & & -1.72 \\
\hline & & & $(0.52)$ & & & $(0.61)$ \\
\hline JEL-development & & & -0.69 & & & -0.62 \\
\hline & & & $(0.52)$ & & & $(0.40)$ \\
\hline JEL-other & & & 0.02 & & & 0.07 \\
\hline & & & $(0.33)$ & & & $(0.38)$ \\
\hline share fem. auth. & & & 0.06 & & & 0.00 \\
\hline & & & $(0.26)$ & & & $(0.18)$ \\
\hline reputation & & & $0.00^{* *}$ & & & 0.00 \\
\hline & & & $(0.00)$ & & & $(0.00)$ \\
\hline number of auth. & & & -0.02 & & & -0.03 \\
\hline & & & $(0.01)$ & & & $(0.03)$ \\
\hline Constant & $3.47^{* * *}$ & $3.00^{* * *}$ & $2.99^{* * *}$ & $3.40^{* * *}$ & $2.94^{* * *}$ & $2.95^{* * *}$ \\
\hline & $(0.06)$ & $(0.03)$ & $(0.14)$ & $(0.04)$ & $(0.02)$ & $(0.16)$ \\
\hline $\mathrm{N}$ & 321 & 319 & 310 & 321 & 319 & 310 \\
\hline Adjusted $\mathrm{R}^{2}$ & 0.41 & 0.42 & 0.49 & 0.40 & 0.41 & 0.48 \\
\hline
\end{tabular}

Notes. OLS regressions with standard errors clustered by journal in parentheses: $* \mathrm{p}<0.10, * * \mathrm{p}<0.05, * * * \mathrm{p}<$ 0.01 . 
Table 7. Impact of Social Ties on Paper Quality (Full Results, only US papers).

\begin{tabular}{|c|c|c|c|c|c|c|}
\hline & \multicolumn{6}{|c|}{ dependent variable: asinh(GS citations) } \\
\hline & (1) & (2) & $(3)$ & $(4)$ & $(5)$ & (6) \\
\hline \multirow[t]{2}{*}{ AER } & $0.68^{* * *}$ & 0.43 & 0.70 & $1.57^{* * *}$ & $1.44^{* * *}$ & $1.49^{* * *}$ \\
\hline & $(0.01)$ & $(0.15)$ & $(0.47)$ & $(0.01)$ & $(0.05)$ & $(0.06)$ \\
\hline \multirow[t]{2}{*}{ JEEA } & $-2.83^{* * *}$ & -2.11 & 0.25 & $0.90^{* * *}$ & $0.80^{* *}$ & $0.94^{* * *}$ \\
\hline & $(0.08)$ & $(0.75)$ & $(0.42)$ & $(0.01)$ & $(0.12)$ & $(0.06)$ \\
\hline \multirow[t]{2}{*}{ minDist } & -0.01 & -0.00 & $-0.03^{*}$ & & & \\
\hline & $(0.00)$ & $(0.02)$ & $(0.01)$ & & & \\
\hline \multirow[t]{2}{*}{$\operatorname{minDist} *$ AER } & $0.21^{* * *}$ & $0.25^{* *}$ & 0.20 & & & \\
\hline & $(0.00)$ & $(0.05)$ & $(0.11)$ & & & \\
\hline \multirow[t]{2}{*}{ minDist * JEEA } & $0.84^{* * *}$ & $0.63^{*}$ & 0.10 & & & \\
\hline & $(0.02)$ & $(0.22)$ & $(0.05)$ & & & \\
\hline \multirow[t]{2}{*}{ any-connection } & & & & $0.22^{* *}$ & $0.10^{*}$ & 0.07 \\
\hline & & & & $(0.03)$ & $(0.02)$ & $(0.09)$ \\
\hline \multirow[t]{2}{*}{ any-connection * AER } & & & & $-0.45^{* * *}$ & $-0.23^{*}$ & -0.03 \\
\hline & & & & $(0.04)$ & $(0.06)$ & $(0.11)$ \\
\hline \multirow[t]{2}{*}{ any-connection * JEEA } & & & & 0.00 & 0.00 & 0.00 \\
\hline & & & & (.) & $()$. & (.) \\
\hline \multirow{2}{*}{ age } & $0.04^{* *}$ & $0.05^{* *}$ & $0.06^{* * *}$ & $0.04^{*}$ & $0.05^{* *}$ & $0.07^{* * *}$ \\
\hline & $(0.01)$ & $(0.01)$ & $(0.01)$ & $(0.01)$ & $(0.01)$ & $(0.01)$ \\
\hline \multirow{2}{*}{ part. per treatment } & & 0.00 & 0.00 & & 0.00 & 0.00 \\
\hline & & $(0.00)$ & $(0.00)$ & & $(0.00)$ & $(0.00)$ \\
\hline \multirow[t]{2}{*}{ treatments } & & 0.07 & 0.05 & & 0.06 & $0.04^{*}$ \\
\hline & & $(0.03)$ & $(0.02)$ & & $(0.03)$ & $(0.01)$ \\
\hline \multirow[t]{2}{*}{ strength of incentives } & & 1.15 & 0.91 & & 0.98 & 0.88 \\
\hline & & $(1.18)$ & $(0.73)$ & & $(0.91)$ & $(0.44)$ \\
\hline \multirow[t]{2}{*}{ pages (EE-equivalent) } & & & -0.01 & & & -0.01 \\
\hline & & & $(0.01)$ & & & $(0.00)$ \\
\hline \multirow[t]{2}{*}{ references } & & & 0.01 & & & $0.01^{*}$ \\
\hline & & & $(0.01)$ & & & $(0.00)$ \\
\hline JEL-micro & & & -0.52 & & & -0.52 \\
\hline & & & $(0.40)$ & & & $(0.34)$ \\
\hline JEL-theory & & & -0.33 & & & -0.34 \\
\hline & & & $(0.27)$ & & & $(0.23)$ \\
\hline JEL-labor & & & $-0.78^{* *}$ & & & -0.60 \\
\hline & & & $(0.15)$ & & & $(0.37)$ \\
\hline JEL-econometrics & & & 0.58 & & & $0.75^{*}$ \\
\hline & & & $(0.23)$ & & & $(0.21)$ \\
\hline JEL-industrial & & & $-1.85^{* * *}$ & & & $-1.92^{* *}$ \\
\hline & & & $(0.08)$ & & & $(0.25)$ \\
\hline JEL-international & & & 0.00 & & & 0.00 \\
\hline & & & (.) & & & (.) \\
\hline JEL-finance & & & $-1.76^{* *}$ & & & $-1.67^{* *}$ \\
\hline & & & $(0.38)$ & & & $(0.39)$ \\
\hline JEL-public & & & -0.41 & & & $-0.52^{*}$ \\
\hline & & & $(0.35)$ & & & $(0.13)$ \\
\hline JEL-health & & & $-2.22^{* * *}$ & & & $-2.26^{* * *}$ \\
\hline & & & $(0.10)$ & & & $(0.14)$ \\
\hline JEL-development & & & $-7.00^{*}$ & & & $-6.95^{*}$ \\
\hline & & & $(1.95)$ & & & $(2.31)$ \\
\hline JEL-other & & & 1.18 & & & 1.17 \\
\hline & & & $(0.69)$ & & & $(0.80)$ \\
\hline share fem. auth. & & & 0.24 & & & 0.22 \\
\hline & & & $(0.18)$ & & & $(0.21)$ \\
\hline reputation & & & $0.00^{* *}$ & & & 0.00 \\
\hline & & & $(0.00)$ & & & $(0.00)$ \\
\hline number of auth. & & & $-0.11^{*}$ & & & -0.15 \\
\hline & & & $(0.04)$ & & & $(0.09)$ \\
\hline Constant & $3.78^{* * *}$ & $2.85^{* * *}$ & $3.42^{* * *}$ & $3.68^{* * *}$ & $2.87^{* * *}$ & $3.24^{* * *}$ \\
\hline & $(0.05)$ & $(0.19)$ & $(0.17)$ & $(0.13)$ & $(0.15)$ & $(0.12)$ \\
\hline $\mathrm{N}$ & 113 & 112 & 111 & 116 & 115 & 114 \\
\hline Adjusted $\mathrm{R}^{2}$ & 0.34 & 0.36 & 0.41 & 0.36 & 0.37 & 0.44 \\
\hline
\end{tabular}

Notes. OLS regressions with standard errors clustered by journal in parentheses: $* \mathrm{p}<0.10,{ }^{* *} \mathrm{p}<0.05, * * * \mathrm{p}<$ 0.01 . 
Table 8. Impact of Social Ties on Paper Quality (Full Results I, WoS Citations).

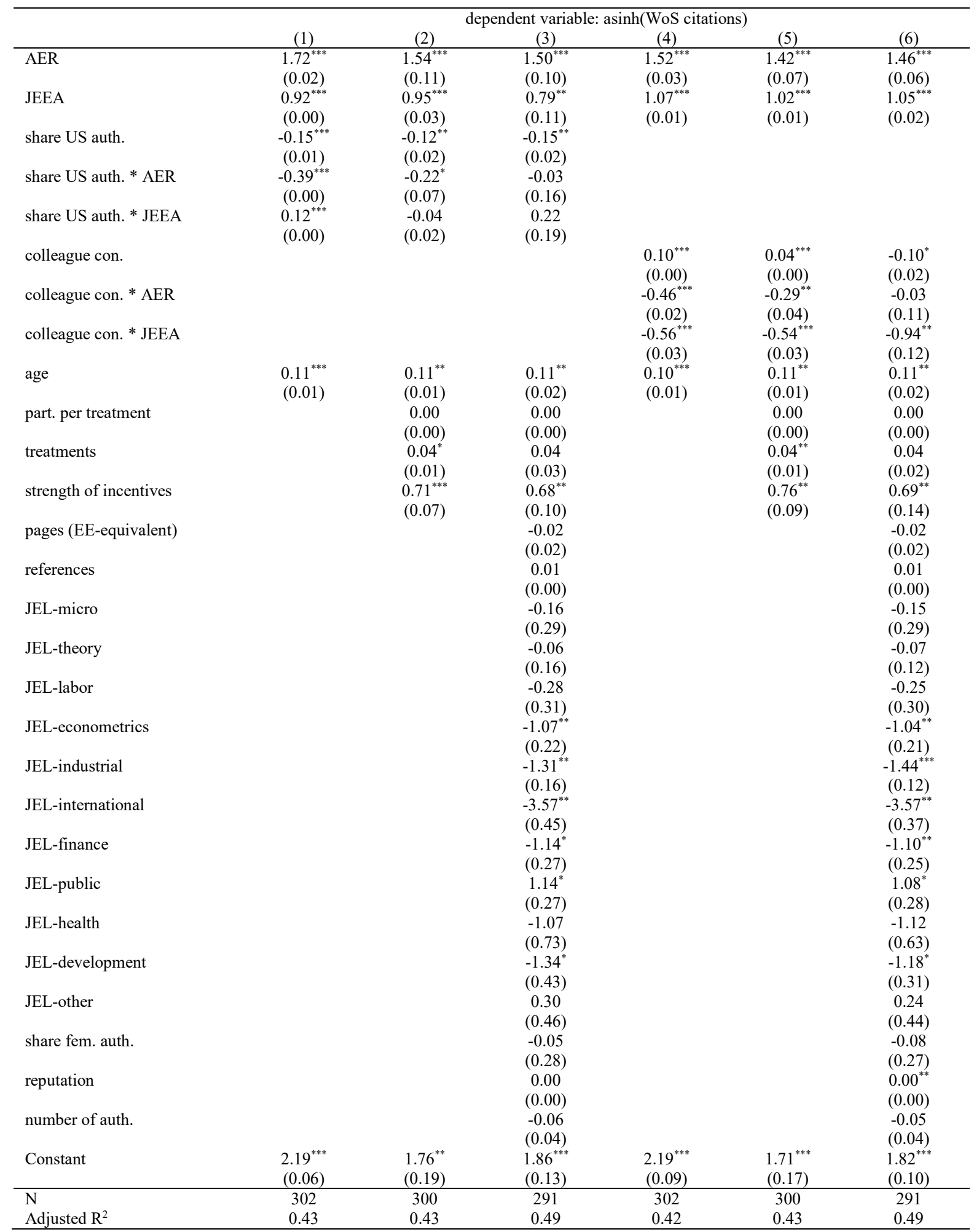

Notes. OLS regressions with standard errors clustered by journal in parentheses: $* \mathrm{p}<0.10,{ }^{* *} \mathrm{p}<0.05, * * * \mathrm{p}<$ 0.01 . 
Table 9. Impact of Social Ties on Paper Quality (Full Results II, WoS Citations).

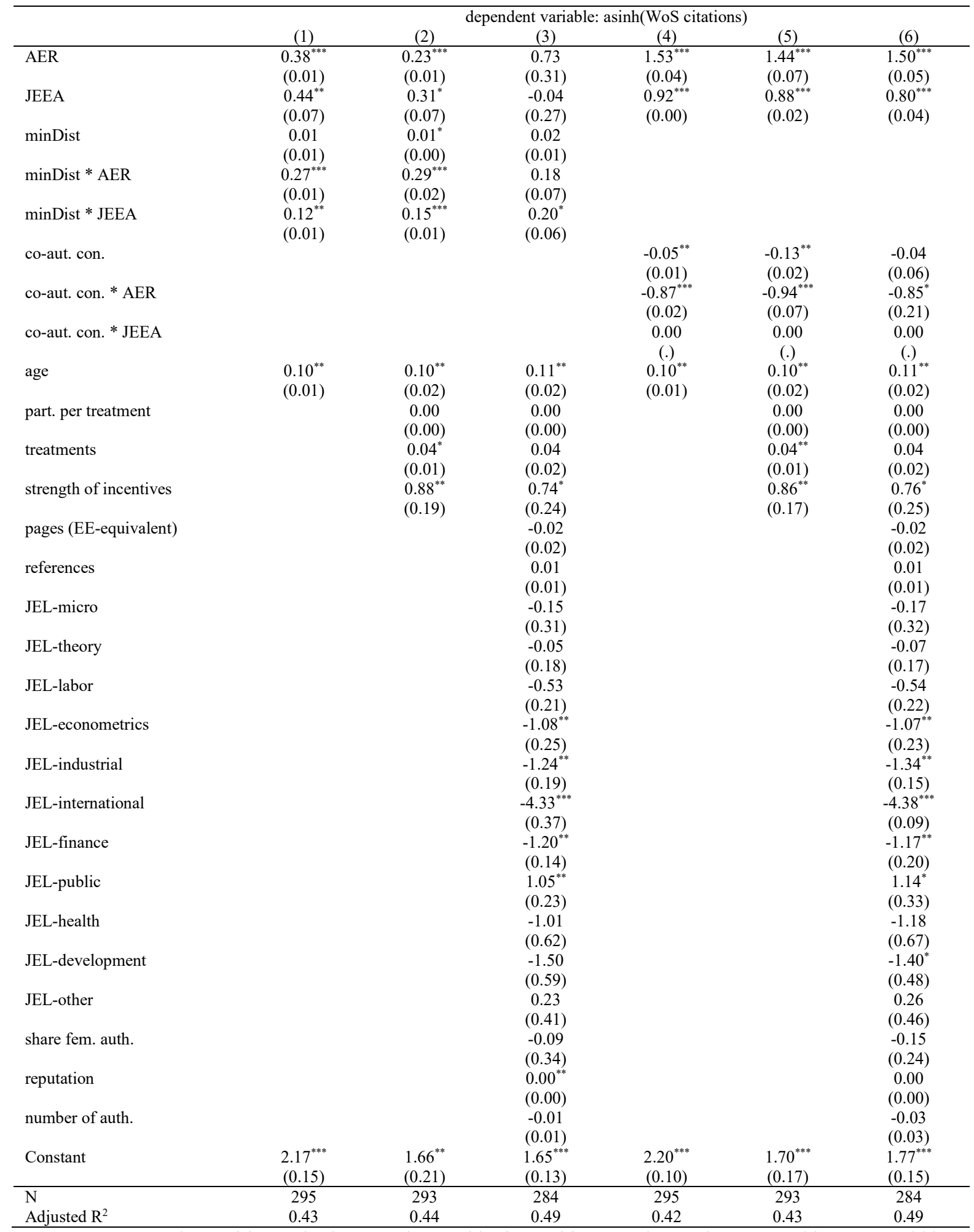

Notes. OLS regressions with standard errors clustered by journal in parentheses: $* \mathrm{p}<0.10, * * \mathrm{p}<0.05, * * * \mathrm{p}<$ 0.01 . 
Table 10. Impact of Social Ties on Paper Quality (Full Results I, Raw Citations).

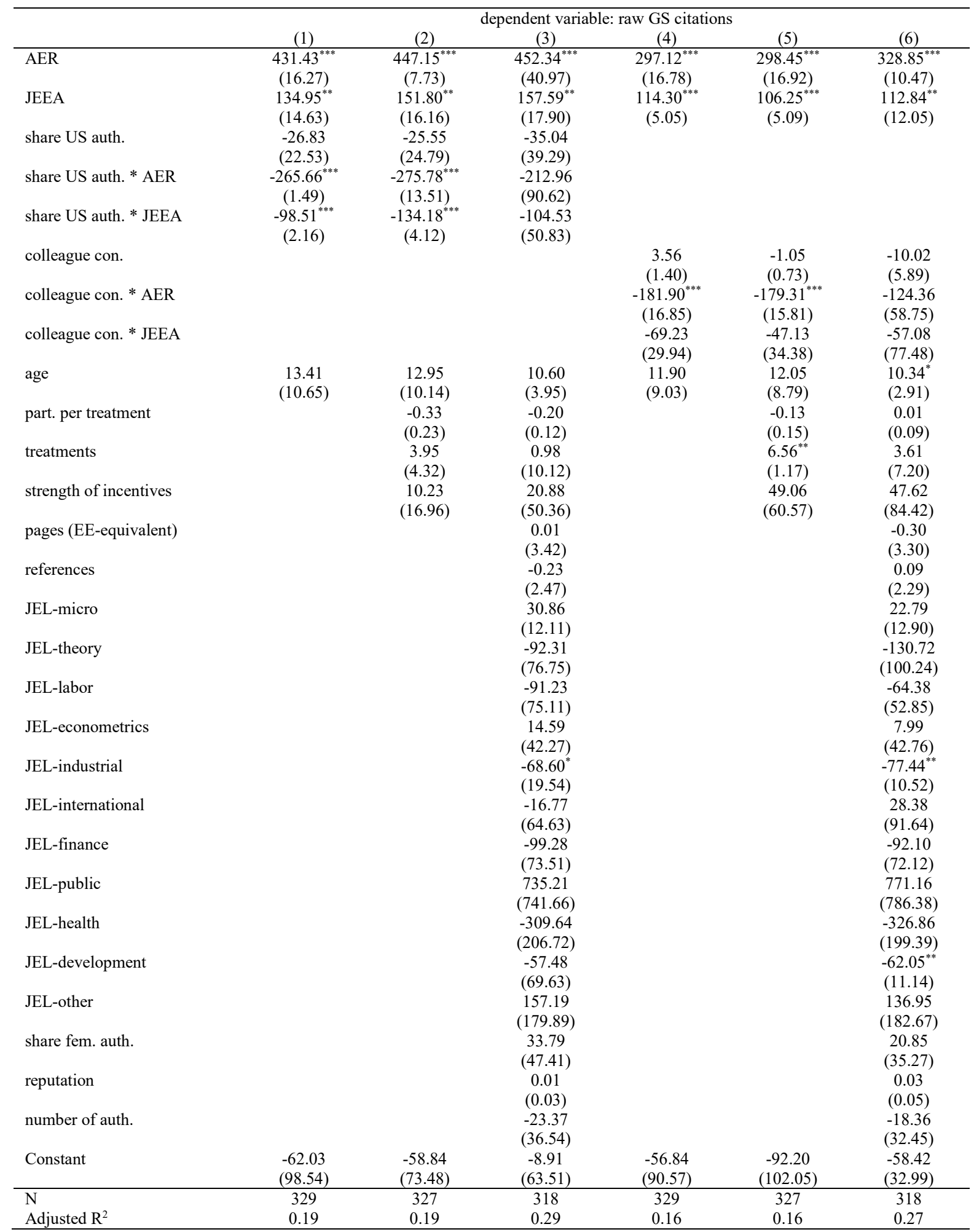

Notes. OLS regressions with standard errors clustered by journal in parentheses: $* \mathrm{p}<0.10,{ }^{* *} \mathrm{p}<0.05,{ }^{* * *} \mathrm{p}<$ 0.01 . 
Table 11. Impact of Social Ties on Paper Quality (Full Results II, Raw Citations).

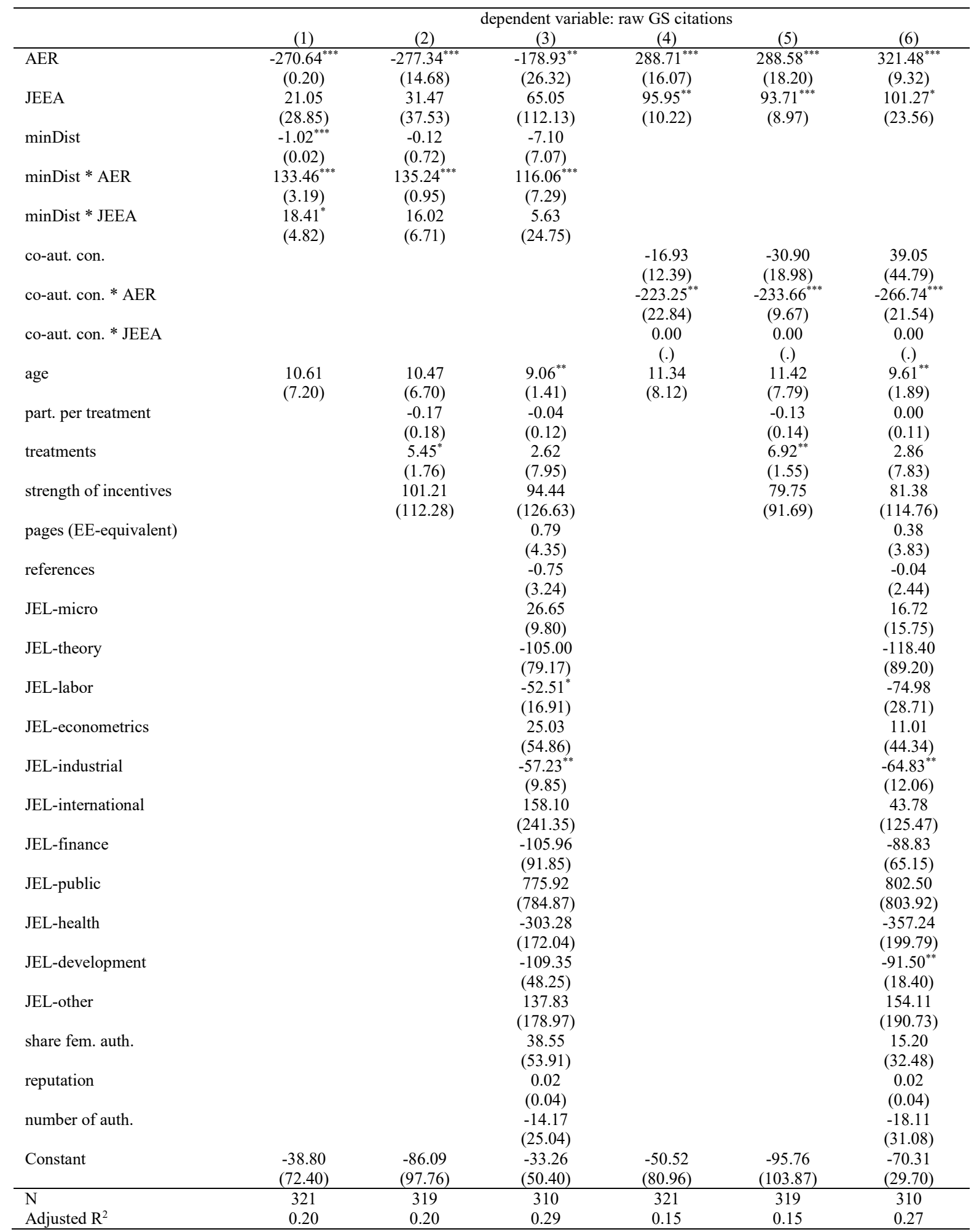

Notes. OLS regressions with standard errors clustered by journal in parentheses: $* \mathrm{p}<0.10,{ }^{* *} \mathrm{p}<0.05,{ }^{* * *} \mathrm{p}<$ 0.01 . 
Table 12. Impact of Social Ties on Paper Quality (Full Results, only US papers, Raw Citations).

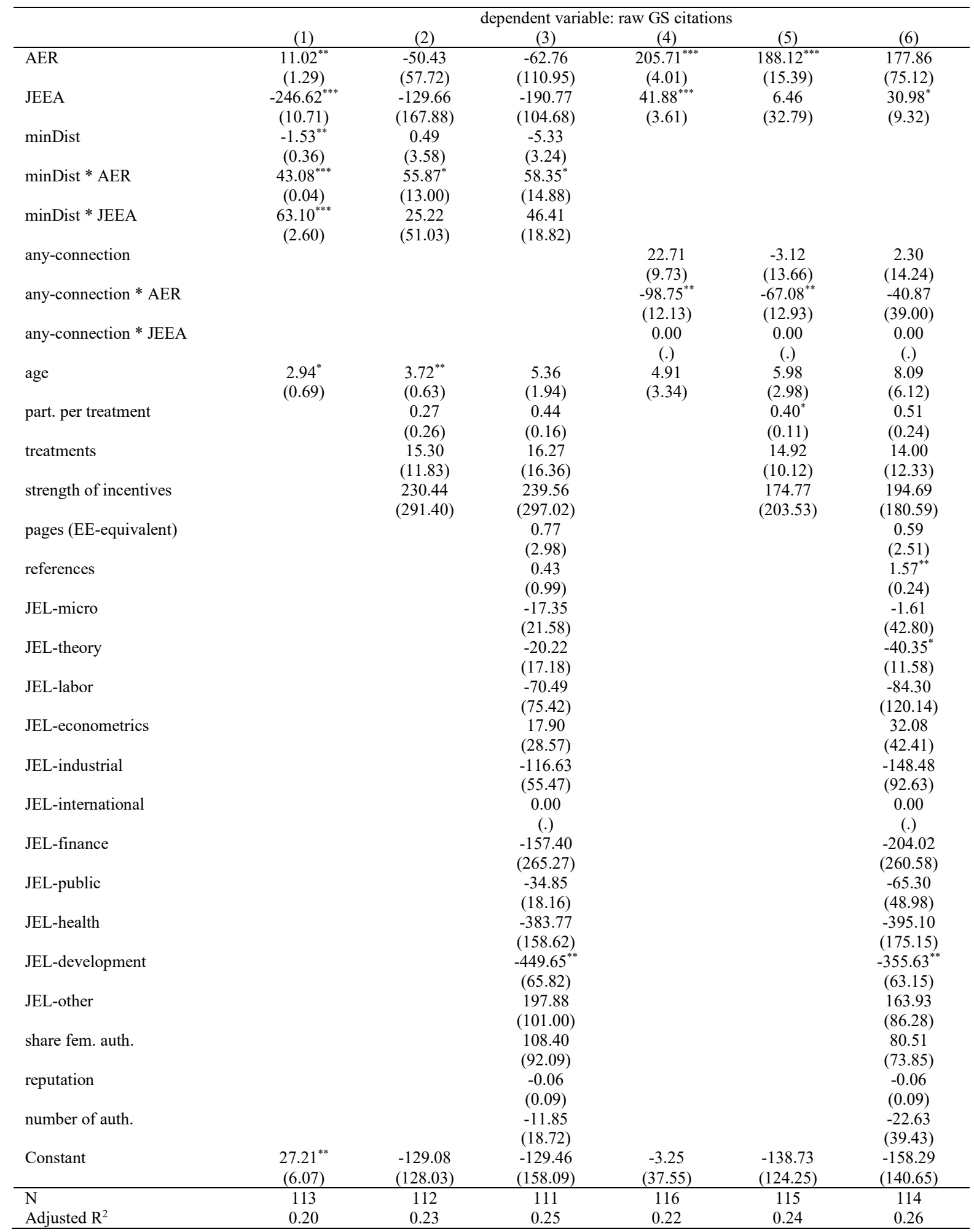

Notes. OLS regressions with standard errors clustered by journal in parentheses: ${ }^{*} \mathrm{p}<0.10,{ }^{* *} \mathrm{p}<0.05,{ }^{* * *} \mathrm{p}<$ 0.01 . 